\title{
The Perceptions of Water Poverty Related Current Issues in South Africa
}

\section{Charles van der Vyver}

\author{
North-West University, Vaal Triangle Campus
} South Africa, charles.vandervyver@nwu.ac.za

\section{Doi:10.5901/ajis.2014.v3n4p57}

\begin{abstract}
Global demand for water is on the increase, and this places increasing pressure on already scarce global supplies. This research aims to determine the perceptions regarding current and future water poverty related issues. All the members of staff of a faculty at one of the leading universities in South Africa formed the participants for this research. A quantitative study was conducted and questionnaires were distributed to the entire population. The research found that although a fair level of awareness does exist, people seem unaware of the impact they can have simply by changing their own water consumption habits. A lot can therefore still be done in an attempt to ensure future supply, both through continuing education, and by elevating water poverty and conservation on the national and international agenda. Future research should focus on evaluating current awareness campaigns and adapting them to ensure relevance and maximum impact.
\end{abstract}

Keywords: Water management, water shortage, water supplies, water consumption.

\section{Introduction}

In recent years it has been widely recognised that water was managed with little regard to the efficiency of its utilisation and with no or very little effective pollution control (Pallett, 1997). South Africa, being a water-stressed country with less than $1700 \mathrm{~m}^{3}$ of water for each person per year (Rand Water, 2008), has limited fresh water resources and budgets for the supply of basic infrastructure services. Currently over 6 million people in South Africa are without access to even a basic level of water supply or have only a very limited level of access (Cullis, 2005). The water poverty situation is further worsened by unawareness of the water scarcity situation and through irresponsible usage.

\section{The South African Context}

South Africa is a water-stressed country (Rand Water, 2008). Water stress is an indicator that is commonly used to measure the degree of water resources vulnerability, and typically occurs when the demand for water exceeds the supply (Perveen \& James, 2011). Water stress causes deterioration of fresh water resources in terms of quantity and quality. Water scarcity occurs when a large number of people in an area do not have access to safe and affordable water to satisfy their needs for drinking, washing or their livelihoods for a significant period of time (Rijsberman, 2005). Rand Water (2008) warns that if South Africans do not learn how to use their limited water supplies wisely, they will move into a water scarcity category - that is, less than $1000 \mathrm{~m}^{3}$ per person per year - by 2025. On a worldwide scale the World Bank estimates that roughly 166 million people in 18 countries are affected by water scarcity and another 270 million people in 11 countries are water stressed (Hemson et al., 2008). According to Wilk \& Jonsson (2013), participatory methods and specifically stakeholder participation are crucial to determine amongst others, the adequacy of local services, as accurate information as possible, and to help implement solutions where they are in fact the most urgently needed. Therefore determining the perceptions of water end-users is extremely important, as awareness of the problem is one of the only ways in which more responsible water usage can be fostered.

This research addresses some of the various needs that were highlighted in the 1994 Reconstruction and Development Program (RDP), which listed "meeting basic needs" as one of its five broad programmes (Melville and Goddard, 1996). Some of the areas that were highlighted in the RDP as being extremely relevant, and therefore in need of research include, amongst others:

- Water, including its provision, sanitation and conservation.

- Social welfare.

This research, either directly or indirectly, assists in addressing all of these needs. 


\section{Research Methodology}

Under the quantitative methodology researchers use the scientific method, which starts with the specific theory and hypotheses, and then quantitatively measure and analyze based on established research procedures (Swanson et al., 2005). It typically consists of five steps which include:

1. Determining the basic questions to be answered by the research. In this research determining the perceptions of people regarding water poverty related issues in the South African context.

2. Determining the participants in the research. Quantitative research benefits greatly from generalizability, or being able to draw conclusions about a population from sample data. The members of staff in a faculty at one of the leading universities in South Africa form the population for this study.

3. Selection of methods to answer the research questions. Data will be gathered through the use of questionnaires.

4. Selection of statistical analysis tools for analyzing the collected data. Performed using the built-in tools available in Microsoft Excel.

5. Performing the interpretation of the results of the analysis based on the statistical significance determined.

The advantages of a case study as a research strategy include (Denscombe, 2003):

- It allows the researcher to deal with the intricacies of complex situations.

- It allows the use of a variety of research methods.

- It fosters the use of multiple sources of data.

- It is suitable for when the researcher has little control over events.

- Concentrates effort on one research site.

- Suitable to both theory-building and theory-testing research.

The personnel of a specific faculty at one of the leading tertiary education institutions in South Africa formed the target population for this research. No sampling took place as questionnaires were distributed to all the members of staff in the faculty. The questionnaires highlighted that participation was completely voluntary, and that results will only be used in a summarised format and for research purposes. The questionnaire consisted of mainly multiple choice questions, the majority of which used the 5-point Likert scale, with two open ended questions at the end. A pilot study was run among the senior members of staff in the faculty, after which the questionnaire was refined before distribution. A 100 members of staff were contacted which returned a response rate of $25 \%$.

\section{Water Management}

During recent years some of the major shortcomings of national water management that have been widely recognised (Clarke and King, 2004; Langford, 2005; Meyer, 2007; Pallett, 1997) include very little or no pollution control, and inefficient utilisation. According to Pallett (1997), the aim of water management should be to supply people with essential water supplies while ensuring that water continues to be shared among all the components of the human and natural environment in a river basin. The importance of good water management is vital in determining the water fate of the majority of the world's population (Clarke and King, 2004).

Management is one of the major problems in the global water sector (Ahmad, 2003), and according to Langford (2005), the reasons why we currently find ourselves in a water and sanitation crisis are:

- Insufficient and decaying infrastructure for water service delivery, especially in deprived rural and urban areas.

- Insufficient capacity and funding for the expansion and maintenance of water supply systems.

- Pollution of traditional water sources, particularly from industrial waste, agricultural runoff and human and animal waste.

- Reduced access to, and depletion of, water resources due to drought, population growth, armed conflict and the dominance of commercial agricultural and industrial activities.

Many researchers (Ahmad, 2003; Cullis, 2005; Sullivan, 2002) suggest that a shift of emphasis to a more holistic approach to water management is necessary. As a first step, the concept of an Integrated Water Resource Management (IWRM) as a holistic approached-based framework for water management was introduced. This approach focuses on poverty reduction and sustainability of ecosystems among other things; in other words to achieve a sustainable water world. The Global Water Partnership (2000:15) defines IWRM as "a process which promotes the co-ordinated development and management of water, land, and related resources in order to maximise the resultant economic and social welfare in an equitable manner without compromising the sustainability of vital ecosystems". 
At the United Nations Conference on the Environment and Development that was held in 1992 in Rio de Janeiro, IWRM was a major item on the agenda. During this conference the various stakeholders came up with an action plan for the world environmental crisis, called Agenda 21. Under this agenda, the four main objectives of IWRM are (Pallett, 1997):

1. To plan the sustainable and rational utilisation, protection, conservation and management of water resources.

2. To identify and strengthen or develop, as required, in particular in developing countries, the appropriate institutional, legal and financial mechanisms to ensure that water policy and its implementation are a catalyst for sustainable social progress and economic growth.

3. To promote a dynamic, iterative, interactive and multisectoral approach to water resources management.

4. To design, implement and evaluate projects and programmes that are both economically efficient and socially appropriate within clearly defined strategies.

Unfortunately, according to Swatuk (2010), although supporting the principle of IWRM, South Africa will experience some difficulties in realising the ideals of IWRM in practice. Examples of some of the contributing factors to these expected difficulties include:

- The loss of more than 1000000 jobs in the first post-apartheid decade, which had resulted in major economic implications.

- Fault lines that have appeared within and between the major political parties.

- Capital flight and the out-migration of skilled workers to other countries, which limit the capacity of the state and society to shift toward more efficient, equitable and sustainable processes of wealth creation.

However, several successful actions have been documented as well, namely (Swatuk, 2010):

- Free basic water provision for all.

- Improved demand management through progressive tariff and taxation policies, removal of alien species, leak detection and repair in urban areas, etc.

- Incentives for farmers and industry to move towards more efficient water usage.

Hemson et al. (2008) have analysed many years of work and development in the global water sector. This analysis has led them to compile the following set of guidelines, which, when adhered to, will greatly improve the effectiveness of any water management entity's efforts:

- Set lower goals, as sufficient funding will not be available, rather than argue strongly for more resources.

- Emphasise the very simplest level of technology with wells and village hand pumps to make local water resources more available to the poor within existing budgets.

- Place responsibility first on communities and second on national governments rather than on international organisations.

- Place the responsibility for initial capital resources on communities and require communities to be responsible for operations and maintenance.

- Make water provision an aspect of community development rather than a public health issue.

- Seek ways in which more can be achieved with more or less the same financial commitment by fixing systems rather than providing greater funding.

- Pay greater attention to the role of women in managing water resources and benefiting from delivery.

- Stress better utilisation of water to improve health conditions, for example personal hygiene and proper sanitation.

Perhaps one of the most well-known examples of poor water management relates to the Aral Sea in Kazakhstan and Uzbekistan. The Aral Sea has shrunk by $66 \%$ in volume and by $50 \%$ in area since 1957, due to the diversion of two rivers that used to feed it for irrigation by the 1960's Soviet government (Clarke and King, 2004). The water level of the Aral Sea has dropped by more than 13 metres, and its mineral content has increased fourfold, which has effectively killed off the entire fish population. It went from a sea supporting 60000 fishermen in producing 40000 tons of fish, to a poisoned wasteland with no fish production. About half the populations of the once seaside Aral towns and villages have fled, leaving the people who were forced to stay in a constant battle with a deadly mix of pollutants. The infant mortality rate in the Aral region is among the highest in the world (Clarke and King, 2004).

\section{Demographics of the Population}

As mentioned previously the response rate for the questionnaire was $25 \%, 25$ respondents. Figure 1 illustrates the age distribution of the respondents, with all four groups fairly well represented. Just over $60 \%$ of the respondents were 
female, which is also a fairly good representation of both genders.

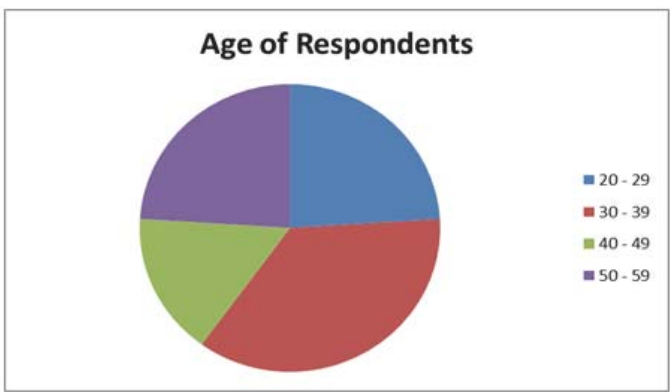

Figure 1: Age of the respondents

Figure 2 illustrates the number of people in the households of the respondents. Out of the 25 respondents almost $80 \%$ indicated that they consider themselves and their households to be responsible water users.

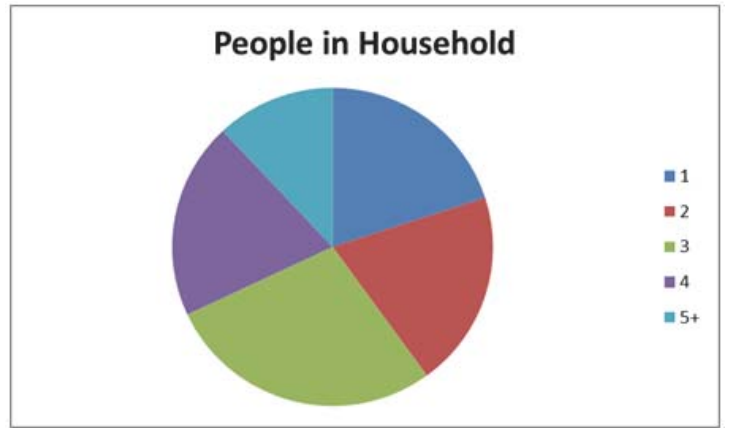

Figure 2: Number of people in each respondent's household

Close to $70 \%$ of the respondents indicated that they have received information regarding responsible water usage in the past. This is represented to a certain degree in figure 3, which illustrates the daily household water consumption in the homes of the respondents. Keep in mind though that the low usage figures might be due to underestimation. There is however no correlation $(r=-0.18$ ) between perceptions of being responsible water users and having received information about responsible usage in the past.

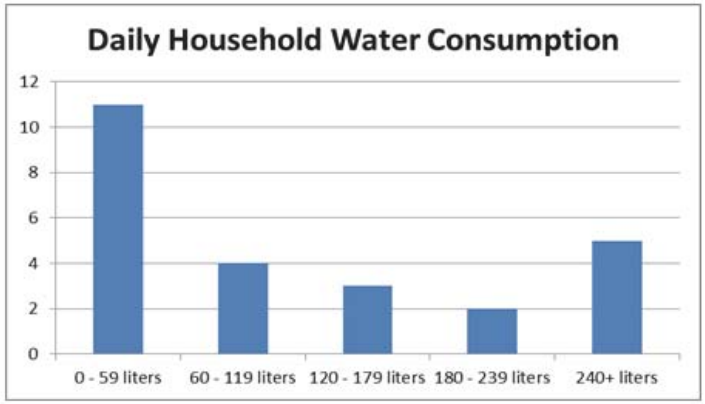

Figure 3: Respondent's Daily Household Water Consumption 
In South Africa provision is made for 6 kilolitres of free water per household per month (as mentioned in section 4). This is based on the World Health Organisation's guideline that each person requires 25 litres of water per day to ensure healthy living, where the average from the respondents was 31,2 litres. Based on a countrywide average of 8 people per household, it equates to 25 litres * 8 people * 30 days $=6000$ litres. The majority of households in the country receive this allocation (Emfuleni Local Municipality, 2010), but limitations to full implementation are for example unmetered stands, flat rate billing, no supplied water service, etc. Only about $40 \%$ of the respondents indicated that they are aware of the free water initiative from government.

\section{Findings}

Understanding people's current perceptions is crucial in planning for the future. When the respondents were asked about South Africa's water supplies various perceptions were identified, as shown in figure 4. The majority of respondents indicated a positive response toward short term supply, the medium term elicited a more negative response, whereas the long term elicited an overwhelming negative response, with no one indicating that they feel South Africa has enough water supplies for the long term. This indicates that there is a certain degree of awareness regarding our future water security and supports the statement made earlier that South Africa is a water-stressed country. With a certain degree of awareness already established the likelihood of successful implementation of interventions to secure future water supply is increased significantly.

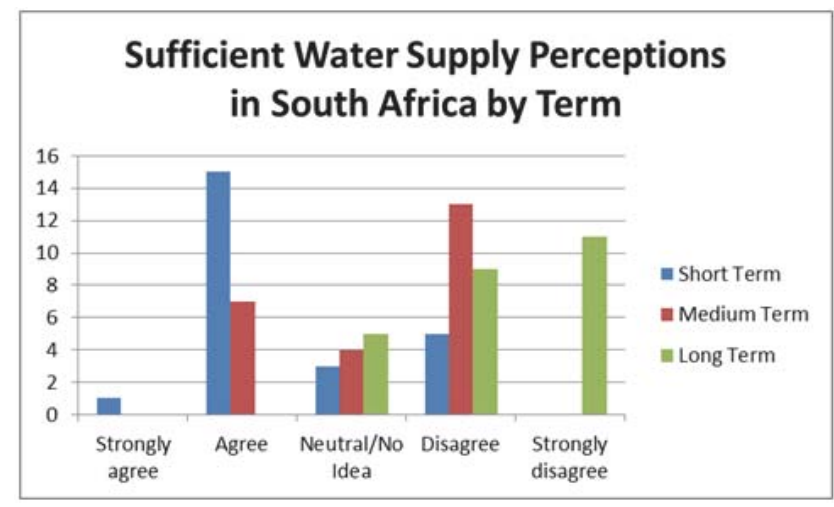

Figure 4: Perceptions Regarding Sufficient South African Water Supply

When the respondents were asked about global water supplies various perceptions were identified, as shown in figure 5 . The perceptions of the respondents regarding sufficient short term supply were divided. Only about $40 \%$ indicated a positive response (similar to the neutral responses), whereas $24 \%$ indicated a negative response. When asked about the medium term the perceptions immediately turned more negative, and when asked about the long term the responses were overwhelmingly negative, except for $12 \%$ positive responses. Despite the increased number of neutral responses, it can be argued that the overall perceptions regarding global water supply is more negative than that for the South African supply. This supports the statement made earlier that a certain level of awareness definitely exists, however a great deal of time and effort has to be invested in ensuring that everyone becomes aware of the scale of the problem, even in countries that do not experience any current water supply issues/concerns. 


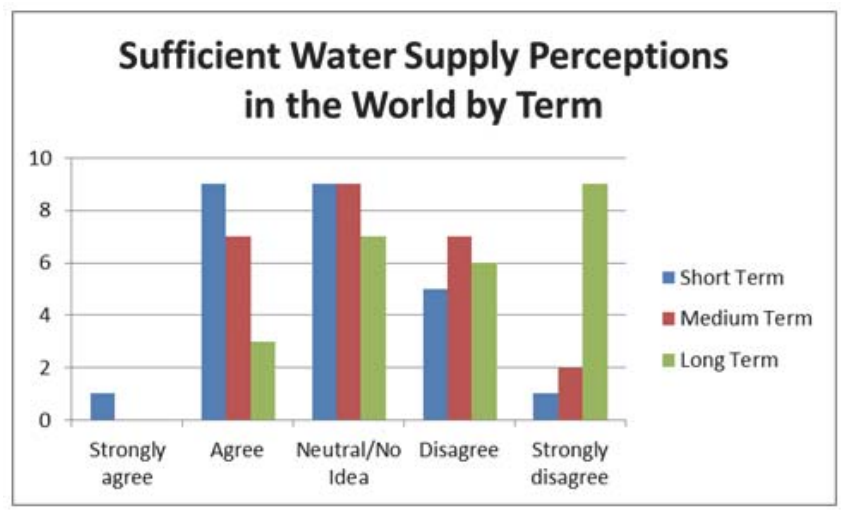

Figure 5: Perceptions Regarding Sufficient Global Water Supply

Figure 6 illustrates the perceptions of the respondents regarding whether mankind should change their water consumption habits to ensure future supply. It had a positive response from everyone, with the majority indicating strongly agree. There were however no neutral or any negative responses. This indicates that people are aware that we are currently over-using our water resources, as was also indicated by figures 4 and 5 . This is however in sharp contrast with the answers obtained when asked whether they should change their own consumption habits. Only $28 \%$ of respondents felt that they needed to change their own habits, $8 \%$ indicated neutral, and an overwhelming $64 \%$ indicated that they feel their water consumption is sufficiently low and that they do not have to change their habits. Therefore they realize that a problem exists, but feel that it is not their concern. This can only be rectified by establishing a clear feeling of ownership amongst all water users, in an attempt to have them realize that the solution starts with them. With the majority of respondents still quite young (as indicated in figure 1), an immediate change towards the better can have far reaching implications for improving our water future.

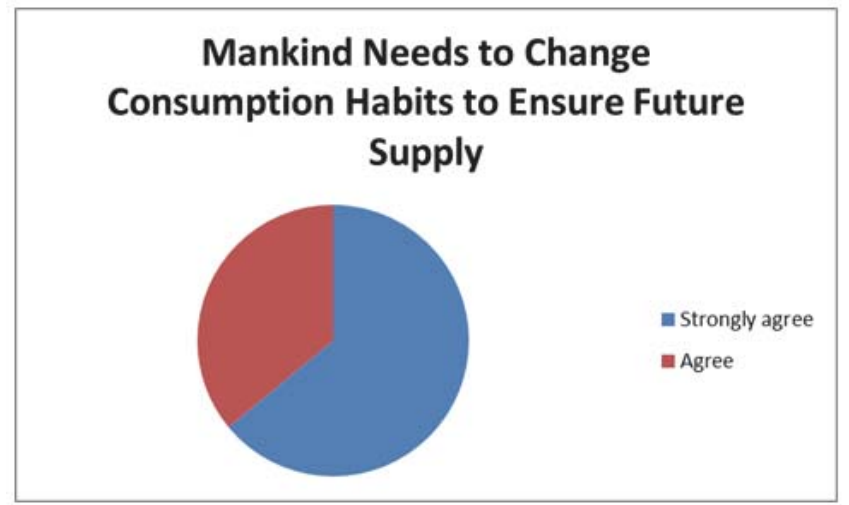

Figure 6: Perceptions Regarding the Changing of Water Consumption Habits

It has been widely documented that water shortages can and will lead to violence (Lewis, 2009; Ruelas-Monjardin, Chavez-Cortes \& Shaw, 2009; Wagner, 2008). This feeling was evident amongst the respondents as well. When asked whether they feel if water shortages might lead to future violence the response was overwhelmingly positive, with $84 \%$ either indicating strongly agree or agree, $12 \%$ indicating neutral, and only $4 \%$ indicating disagree. The respondents are therefore also aware that the problem stretches much further than insufficient supply and an ever increasing demand, but that violence and perhaps even war might start as part of efforts to secure future supply. One respondent indicated they believe the next world war might start due to water shortages. The sooner we therefore start to change our ways of thinking, the less likely the probability that violence will occur. 


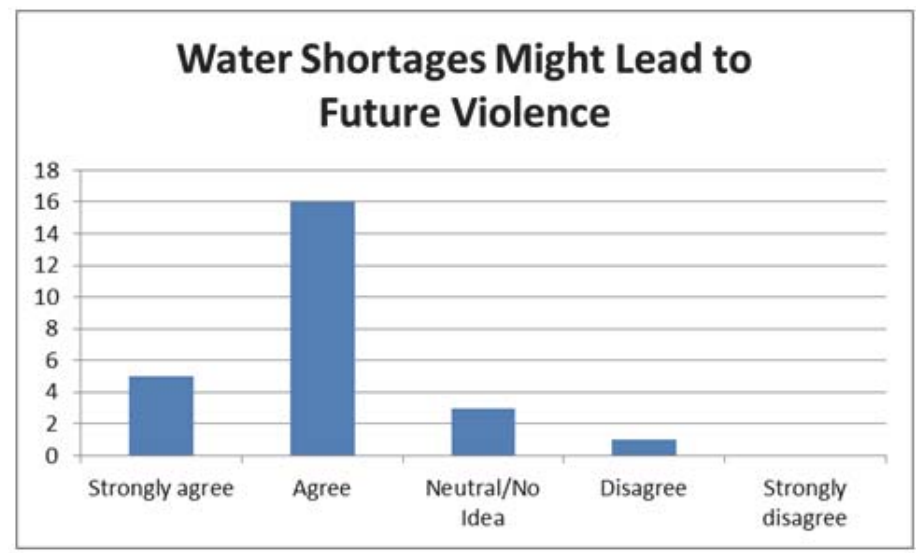

Figure 7: Perceptions Regarding Possible Future Water Related Violence

\section{Conclusion}

Even though awareness of the global water crisis is on the increase, there is still much that can be done to try and ensure future supply. The research found that although a fair level of awareness does exist, people seem unaware of the impact they can have simply by changing their own water consumption habits. One of the current awareness campaigns that exist is the WaterWise campaign of Rand Water, one of the bulk water service providers in the country and also the provider to the municipalities of the respondents, of which only $56 \%$ of the respondents were aware. Responsible water usage also forms part of the primary school curriculum and is disseminated to learners in grade 4 . This should theoretically have far-reaching effects, but does not seem to leave a lasting impression given the levels of awareness.

A lot can therefore still be done in an attempt to ensure future supply, both through continuing education, and by elevating water poverty and conservation on the national and international agenda. Future research should focus on evaluating current awareness campaigns and adapting them to ensure relevance and maximum impact.

\section{References}

Ahmad, Q. K. 2003. Towards poverty alleviation: the water sector perspectives, Water Resources Development, 19(2), pp. 263-277.

Clarke, R. \& King, J. 2004. The Atlas of Water. Mapping the world's most critical resource. Earthscan, 8 - 12 Camden High Street, London, NW1 0JH, United Kingdom.

Cullis, J. D. S. 2005. Water poverty mapping: development and introduction using a case study at the local municipal scale for the Eastern Cape. Water Research Commission, TT 250/05, August.

Denscombe, M. 2003. The Good Research Guide, $2^{\text {nd }}$ Edition. Open University Press, 325 Chestnut Street, Philadelphia, PA 19106, USA.

Emfuleni Local Municipality (ELM). 2010. Integrated Development Plan 2009/10.

Global Water Partnership. 2000. Towards water security: a framework for action, Stockholm, Global Water Partnership.

Hemson, D., Kulindwa, K., Lein, H. \& Mascarenhas, A. 2008. Poverty and Water. Explorations of the reciprocal relationship. Zed Books Ltd, 7 Cynthia Street, London, N1 9JF, United Kingdom.

Hemson, D., Kulindwa, K., Lein, H. \& Mascarenhas, A. 2008. Poverty and Water. Explorations of the reciprocal relationship. Zed Books Ltd, 7 Cynthia Street, London, N1 9JF, United Kingdom.

Langford, M. 2005. The United Nations concept of water as a human right: a new paradigm for old problems? Water Resources Development, 21(2), pp. $273-282$.

Lewis, L. 2009. Fears of violence as world's water begins to run out. The Times (UK), p. 31.

Melville, S. \& Goddard, W. 1996. Research Methodology. Juta \& Co Limited, P.O. Box 14373, Kenwyn, 7790.

Meyer, W. N. 2007. The economics of water, water for life; sanitation for dignity. Van Schaik Publishers, 1064 Arcadia Street, Hatfield Pretoria.

Pallett, J. 1997. Sharing water in Southern Africa. Desert Research Foundation of Namibia, PO Box 20232, Windhoek, Namibia.

Perveen, S. \& James, L. A. 2011. Scale invariance of water stress and scarcity indicators: Facilitating cross-scale comparisons of water resources vulnerability. Applied Geography, 31(2011), pp. 321 - 328.

Rand Water. 2008. http://www.wisa.org.za/patrons/randwater/index2.html [2 October 2008]. 
Rijsberman, F. R. 2005. Water scarcity: Fact or fiction? Agricultural Water Management, 80(2006), pp. 5 - 22.

Ruelas-Monjardin, L. C., Chavez-Cortes, J. M. \& Shaw, D. P. 2009. Scarcity and conflict, key problems in water management: a Mexican case study. Local Environment, Vol. 14(8), pp. $765-782$.

Sullivan, C. A., Meigh, J. R. \& Fediw, T. S. 2002. Derivation and Testing of the Water Poverty Index Phase 1: Final Report. DFID.

Swanson, R. A. \& Holton, E. F. 3rd. 2005. Research in organizations: Foundations and methods of inquiry. San Francisco, BerrettKoehler.

Swatuk, L. A. 2010. The State and Water Resources Development through the Lens of History: A South African Case Study. Water Alternatives, Vol. 3(3), pp.521 - 536.

Wagner, C. G. 2008. Water and Violence: Are Scarcity and Conflict Connected? Futurist, Vol. 42(3), p. 3.

Wilk, J. \& Jonsson A. C. 2013. From Water Poverty to Water Prosperity - A More Participatory Approach to Studying Local Water Resources Management. Water Resources Management, Vol. 27, pp. 695 - 713. 